\title{
Sexual Dimorphism of Femur in Maharashtraian Population
}

\author{
Rajeshwari. S. Bhosale', Dr. B. R. Zambare² \\ (Department of anatomy, padmashree vithalrao vikhe patil foundation's medical college / Maharashtra \\ University of health sciences, India)
}

\begin{abstract}
Determination of sex of unknown skeleton remains is the Most important step in the identification process, Racial and regional differences in the populations create and maintain specificity in their dimorphic characteristics moreover considering continued secular changes in the population structure constant revision of osteomelric standards becomes mandatory, in order to establish osteometric standards for the femur of Maharashtraian populations, 200 adult femora of known sex (96-M; 104-F) were collected in the department of Anatomy of Padmashree Vithalrao Vikhe Patil medical college Ahmednagar's a total of six standard parameters were taken and analysed stastically, the accuracy of the Sex prediction ranged from 70.5\% ti $83.6 \%$ using Single Variables, the length, maximum diameter of head, miashaft circumference, maximum antesoposterior diameter of medial and lateral epicondyle and bicondylar width showed significant differences in male and female femora with accuracy of $90.2 \%$ the result clearly indicates the importance of these variables in identification of sex from femur.
\end{abstract}

Keywords-Femora, Sex Determination, Skeleton, condyle

\section{Introduction}

Most of the techniques presently available for sexual assesment of human skeletal remains can be used only on well preserved bones from relatively complete skeletons, very few reliable means of sexing are available to the ostelogists confronted with poorly preserved bones or fragmentary or mixed skeletons, an example of this is that one of the most accurate means of sexing the pelvis is dependant on the preservation of ospubis is (Phenice 1969), Unfortunately this part of pelvis is not well preserved and in completely missing from some skeletal Collections, Assessment of sex can be done by visual inspections or by taking measurements and employing discriminate functions, even well preserved bones can cause problems in sex determination when muiltple remains are present, so there is a definite need for techniques of sexual determination which will be used for poorly preserved remains and also individual bones.

All the techniques which require the measurement of dia,meters circumference or cross sectional areas so far as tubular bones are concerned may provide the needed means for sexing fragmentary remains.

Hence statistical or morphological analyses of long bones either individual or in combination has been done for the purpose of sex determination, however certain fundamental deficiencies have been noted in traditional anthropological methods, the traditional methods of measurements on the bone are done

without any reference on how the bone lies approximately in anatomical position is the living, this is liable to deprive the workers of the identity of the points of stress and strain which leave their imprints on the

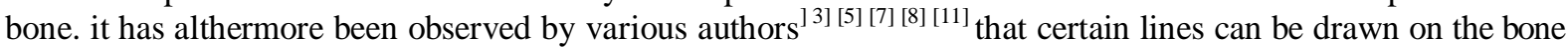
to represent the axis by mere eye judgement' upon the logic that axial skeleton weight of males is relatively and absolutely more than that of females [Willians etal 1989]

Hence based on this argument using the most minimal osteometric measurements an attempt has been made to investigate the sexual dimorphism of femur.

\section{AIM}

The aim of this study in to establish a method of discrimination which will provide an accurate means of distinguishing features between The males and females and which requires the fewest osteometric measurements which will help forensic experts to come to a conclusion from the skeletal remains.

\section{Material And Method}

The present study was conducted in the Dept of anatomy of Padmashree Vithal Rao Vikhe Patil Medical College Ahmadnagar on 200 dry intact adult femora of both sex`s out of which 100 males (50 Rt and $50 \mathrm{lft}$ ) and 100 females (50 Rt and $50 \mathrm{lft}$ ). All bones included for the study belong to a homogenous population, all bones were documented for sex and race and all belong to a population of Maharashtra, these 
were cleaned well to remove soft tissue and cartilage and were thoroughly dried, and completed which is seen by complete fusion of proximal and distal femoral epiphysis.

All those femora which showed pathologies like cortical bone deterioration or an extreme osteophytic activity were excluded from the study.

\section{Method}

A total of six set of measurements were taken on each femur

1) Maximum length

2) Maximum diameter of head

3) Midshaft circumference

4) Maximum (AP) diameter of femoral shaft.

5) Antero posterior diameter of epicodyles (Bicondylan Width)

The materials utilized for measuring these parameters were a caliper, thread, scale, Measuring

Tape and divider.

1) Maximum length :- This was measured by keeping the bone in anatomical position, from the highest point on the head of femur (A) to the lower extreme particular margin of the lower end of femur (B) using a measuring tape;

2) Maximum anterpoposterior diameter of head and shaft :-

The Maximum anteroposterior diameter of the head was marked by a point on the anterior aspect of the head to a point on the posterior aspect of the head, a technique followed in earlier (1988) by brauer, McLaughlin and Bruce (1985) ${ }^{[1][6]}$

The Maximum anterpopsterior diameter of head and shaft of femur is marked between the inferior margin of Gluteal taberosity to a point where the 2 lips of lines Aspera divide to from the Supracondylar lines.

Table: - Statistical analysis of Parameters

\begin{tabular}{|c|c|c|c|c|c|}
\hline S.No & Parameter femur & & Male $[50]$ & Female [50] & P-Value \\
\hline \multirow[t]{2}{*}{1} & \multirow[t]{2}{*}{ Length } & $\mathrm{R}[50]$ & $40.6 \pm 2053$ & $38.8 \pm 1.2$ & $0.0001=$ \\
\hline & & L $[50]$ & $40 \pm 1.06$ & $38.8 \pm 1.2$ & $0.001 *$ \\
\hline \multirow[t]{2}{*}{2} & \multirow{2}{*}{$\begin{array}{l}\text { Max.Diameter } \\
\text { of Head }\end{array}$} & $\mathrm{R}[50]$ & $4.6 \pm 0.36$ & $3.82 \pm 016$ & $0.001^{*}$ \\
\hline & & L $[50]$ & $4.76 \pm .21$ & $3.82 \pm .06$ & $0.001^{*}$ \\
\hline & & & & & \\
\hline \multirow[t]{2}{*}{3} & \multirow{2}{*}{$\begin{array}{l}\text { Mid shaft } \\
\text { circumference }\end{array}$} & $R[50]$ & $8.0 \pm 0.28$ & $7.19 \pm 0.16$ & $0.001^{*}$ \\
\hline & & L $[50]$ & $7.78 \pm 0.27$ & $7.16 \pm 0.2$ & $0.001^{*}$ \\
\hline \multirow{3}{*}{4} & \multirow{3}{*}{$\begin{array}{l}\text { Max A-P } \\
\text { Diameter }\end{array}$} & & & & \\
\hline & & $R[50]$ & $3.02 \pm 0.22$ & $2.60 \pm 0.18$ & $0.001 *$ \\
\hline & & L $[50]$ & $2.90 \pm .23$ & $2.60 \pm 0.18$ & $0.001 *$ \\
\hline \multirow[t]{2}{*}{5} & \multirow[t]{2}{*}{ Bicondylar width } & $\mathrm{R}[50]$ & $7.36 \pm 0.21$ & $6.83 \pm 0.2$ & $0.001 *$ \\
\hline & & L $[50]$ & $7.50 \pm 0.2$ & $6.84 \pm 0.23$ & $0.001 *$ \\
\hline & & & & & \\
\hline \multirow[t]{2}{*}{6} & \multirow{2}{*}{$\begin{array}{l}\text { A-P Diameter of } \\
\text { M-Epicondyle }\end{array}$} & $R[50]$ & $1.68 \pm 0.3$ & $2.06 \pm 0.3$ & $0.001^{*}$ \\
\hline & & L $[50]$ & $1.84 \pm 0.16$ & $2.06 \pm 0.3$ & $0.001^{*}$ \\
\hline & & & & & \\
\hline \multirow[t]{2}{*}{7} & \multirow{2}{*}{$\begin{array}{l}\text { A-P Diameter of } \\
\text { L-Epicondyle }\end{array}$} & $R[50]$ & $1.69 \pm 0.2$ & $1.66 \pm 0.2$ & 0.412 \\
\hline & & L $[50]$ & $1.79 \pm 0.14$ & $1.77 \pm 0.13$ & 0.462 \\
\hline
\end{tabular}

3) Midshaft circumference :-

A midpoint was marked at a level on the Maximum vertical length of femur and midshaft circumference was measured around this point using a thread on a measuring tape.

4) Maximum anteroposterior diameter of epicondyles :-

The medial and lateral epicondyles were indentified and anteroposterior diameter was measured using divider and measuring scale.

Bicondylar Width :-

The technique used by Martin and sellers (1957) ${ }^{(7)}$ was followed the distance between the most projected points on the epicondyles was measured. 
The above Data was analysed statistically and tabulated which was used to determine the optional combination of variables for assessment of sex.

\section{OBSERVATION}

The above study revealed that the following parameters were more in females than in males - length, maximum diameter of head midshaft circumference, maximum anteroposterior diameter of the medial and lateral epicondyle and bicondylar width these parameters were statistically significant having $(\mathrm{P}<0.05)$.

The anteroposterior diameter of medial epicondyle was more in female as compared to the male which was statistically significant $(\mathrm{P}<0.05)$

The anteroposterior diameter of lateral epicdondyle was seen to be more in males as compared to females but still was not significant statistically $(\mathrm{P}<0.05)$.

\section{Discussion}

The best method to identify a person is by using fingerrinting system and DNA test, this helps us to determine the individuality of a person.

Using adult pelvis or scull, sex determination can be done from distinguishing marks on the male and female bones which is considered to be accurate in $90 \%$ of the cases.

Singh and Shamer singh $(1972)^{[1011]}$ concluded that for determining sex of adult femora length as parameter is the best guide provided if it has crossed the demartkating point, according to them the right femora which measures $44.5 \mathrm{~cm}$ and above can be classified as male and those measuring less than $37.7 \mathrm{~cm}$ are female; considering the left femora those that measure $44.2 \mathrm{~cm}$ and above are classified as male and below $37.25 \mathrm{~cm}$ are the female.However another important factor to classify the left femora is the bicondylar width which is the best usefull measurement and the average bicondylar width is $7.12 \mathrm{~cm} \pm 0.4^{(12)}$

A regional variation and downward gradient from north to South was observed is the study done by kate (1964) ${ }^{[13]}$ who worked on femora of different regions of India, according to kate in giving a medico legal opinion the average of a particular region must be considered for comparison, he carried out a study on 50 femora in wet and dry conditions and reported that the articular cartilage added a length of $2.8 \mathrm{~cm}$ on an average with a range of 1 to $4 \mathrm{~mm}$.

The length of femora in present study was $37 \mathrm{~cm}-48 \mathrm{~cm}$ in males and $37 \mathrm{~cm}-44 \mathrm{~cm}$ in female femora.

The measurement of Anteroposterior diameter of the shaft of femora in the present stusy was $2.6-3.7$ $\mathrm{cm}$ in maless and $2.4-3.2 \mathrm{~cm}$ in female femora, hence it was evident that no sufficient data was available on Maharashtraian population as mentioned by Ruma Purkait $(1989){ }^{[9]}$ Hence this finding on the present study was a New entity.

The measurement on the midshaft circumference in the present study was $7.2-8.8 \mathrm{~cm}$ in males and in female femora it was $6.2-7.8 \mathrm{~cm}$ which revealed no significant difference in males and females.

Considering the anteroposterior diameter of the medial epicondyle, in the present study showed significant difference, the medial epicondyle on the left side in males was $1.84 \pm 16$, whereas in females it was $2.07 \pm 26$, on the other hand in males, the diameter of the medial epicondyle on the right side was $1.69 \pm 3.1$ and in females ir was $2.07 \pm 27$, the measurement of the medial epicondyle in females was quite large than males on both sides this may be due to a wider pelvis in females.

Considering the lower end of femur it is seen to be inclined medially, during weight transmission this inclination helps the body weight to be kept closer to the centre of gravity; in females the wider pelvis increases the inclinity so that the weight is transmitted along a line which passes through the medial epicondyle and condyle of femora, Hence due to this mode of weight transmission the medial epicondyle was wider in females, although other measurements in females were comparably lesser than the measurements which were found in males.

Similarly the average bicondylar width in males in the present study on the left side was $7.6 \pm 19$ and was $6.9 \pm 24$ in females, on the right side in males it showed $7.4 \pm 22$ and in females it was found to be $6.9 \pm 19$ which was statistically Significant; A Study carried out by Enock Prabhakar the bicondylar width (1988) ${ }^{\text {[ 2] }}$ among North Indians population was 7.8 in males and 7.2 in the females.

Certain facts regarding femora are note worthy besides the points for sex determination is that femora ossifies from 5 Centers of ossification one each for the shaft, head, greater trochanter, lesser trochanter, and the lower end. The head fuses with rest of the bone at $14 \mathrm{yrs}$ of age in females and $17 \mathrm{yrs}$ in males, and the lower and at 16 yrs of age in females and 18 yrs in males ${ }^{[13}$ ]

There is very scanty literature available on sexual dimorphism of femora based on anteroposterior diameter of epicondyles. 


\section{Conclusion}

In the present study it was noted that all measurements were more in males, the average width of medial epicondyle is more in females.

The average width of lateral epicondyle was more is males but was not statistically significant.

This study is useful in the field of forensic osteology and anthropometry for the identification of skeletal remains.

This study has a great limitation because of the small amount of samples which were studied.

\section{Journal Papers:}

\section{Referencs}

[1]. Ingalls NM (1924). Studies on the femur. Am. J. Phys. Anthropol,7 : 207-55.

[2]. Singh IP and Bhasin MK(1989). Anthropometry, Kamala Raj Enterprises, Delhi.

[3]. Purkait R (2001). Review of Anthropometric techniques 123-29. In: Advances in Forensic Science. MK Bhasin and S Nath(Edn). University of Delhi, Delhi. MacLaughlin SM and Bruce MF (1985)

[4]. A simple univariate technique for determining sex from fragmentary femora: Its application to a Scottish short cist population, American Journal of Physical Anthropology 67: 281-88.

[5]. Singh,S.P and Singh,S (1972 A). The sexing of adult femora: Demarking points for Varanasi zone, Journal of the Indian Academy of Forensic Sciences, 11:1-6.

[6]. Singh SP and Singh S (1972B). Identification of sex from the head of the femur: The demarking points for Varanasi zone, Indian Medical Gazette 11:45-49.

[7]. Kate (1964). Journal of Anatomical Society of India(JASI) Dec. 81-84.

\section{THESIS}

[1] Purkait R (1989a). Sex Determination from Human Long Bones of Madhya Pradesh, India,Ph.d. Dissertation , University of Delhi, Delhi

\section{BOOKS}

[1]. Pearson K and Bell J (1917/1919). The study of the long bones of the English skeleton-I- the femur.In:Drapers' Co. Research Mem. University of London Chapters 1-4 Biometric Series X.

[2]. Martin R and Saller K (1957). Lehrbuch der Anthropologie. Vol. 1 and Vol. 2, Gustav Fisher Verlag, Stuttgart.

[3]. Krogman WM and Iscan MY (1986)

[4]. Human Skeleton in Forensic Medicine. 2nd Edn., Charles C. Thomas, Springfield

[5]. William PL, Warwick R, Dyson M, and Bannister LH (1989).

[6]. In: Gray’s Anatomy. Edn.36, Churchill Livingston, Edinburgh, 396.

[7]. Brauer G.(1988) Osteometrie in anthropologie: Handbuch der vergleichenden biologie des Menschen. Ban 1, Wesen and methoden der

[8]. Subrahmanyan BV (2004). In: Modi’s Medical Jurisprudence and Toxicology. 22nd Edn. Lexis Nexis, Butterworths, 119-21.

[9]. Enock Prabhakar P (1988). In: Practical Medico-Legal Manual, a publication of Indian Academy of Forensic Medicine. 